\section{CRISIS LOSSES OF PROFESSIONAL ACTIVITY AT «THIRD AGE»}

Elvira Symanyuk, Department of General and Social Psychology, Ural Federal University. E-mail: e.e.symaniuk@urfu.ru

Introduction: Current developments in socia and economic spheres, in particular - a rise of retiremen age in many countries have heightened the need for research into psychology of people of 'the third age'. A conceptual focus in this research is placed on analyzing characteristic features of professional development at an old age, finding out factors that contribute to effective professional activity at this age and eventually working out technologies that facilitate coping with a profession loss crisis and acquiring a new social role.

Profession loss crisis is a last normative crisis of professional development. This crisis is caused by an end of a person's professional career when he / she retires. Many employees face crisis in a pre-retiremen period that is connected with mastering a new social role and behavior patterns, making plans for future. Retirement is inevitably accompanied by reducing a social and professional field as well as losing financia resources. A degree of the crisis depends on a characte of professional activity (manual labor workers undergo this process more smoothly), marital and health status. Coping with the crisis can be twofold: either restoration of life interrupted by the crisis, its rebirth, or ts transformation into new life as such. In any of thes cases we are talking about formation of one's own life self-creation and life construction.

Successful crisis resolution stimulates an inflow of person's strength, a desire to master new spheres of reality, increases one's motivation for achievements, contributes to appearing of new abilities.

Factors that determine crises of teachers professional development can be divided subjective and objective groups. A group of objective factors comprise a change of a main activity or a way of doing it, a change of a social development situation, age-dependen psychological and psychophysiological changes professional deformation and stagnation, deterioration or improvement of social and economic situation, fortuitous or unfavorable events.

A second group of factors is caused by subjective personality qualities: inner conditions of personality development, person's activity that is necessary for selfdevelopment.

Zeer E. F. Psychology of Professions; Ural State Professional and .

Ananyev. Voprosy Psychologii, 1986 № 5, Pp. 104-112.
Methods: A pilot research study of professional development crises was carried out during 2016-2018 using sychobiographical and critical event methods that relate to the genetic method of personality research. The biographical method contributes to analyzing a dynamic process of person's professional development at all stages: option, professional training, professional adaptation, primary and secondary professionalism and mastery as well as creating conditions for identifying critical periods in this process

The survey was attended by teachers of educational nstitutions aged 50 to 60 . A total of 191 respondents participated in the study.

n order to study a profession loss crisis a formalized biographical questionnaire by V.G. Norkidze was used that was modified by E.F. Zeer. According to a research procedure teachers were asked to write an essay based on the questionnaire. The scope of work was not limited. Time imit for writing psychobiographes was 2 hours.

Data processing was carried out using content analysis method for identifying and assessing specific characteristics of texts and other information items. The texts obtained in the course of the study were considered as personal, unofficial primary target documents, since when writing free-form biographies, the influence of the researcher is less than while filling a questionnaire or during a conversation. Psychobiographies were a respondents' retrospective analysis of their professional development

The purpose of the content analysis was to identify psychological characteristics of the profession loss crisis of teachers.

Conclusions: The profession loss crises occur at the final stage of professional development. Due to random events $(44.3 \%)$, unfavorable circumstances $(23.2 \%)$ or worsening socio-economic conditions $(21 \%)$, these crises violate the trajectory of professional development.

Anxiety over a mismatch of professional activity with expectations is characteristic of this crisis (67.5\%). Performing professional functions starts to be burdening due to various reasons (14\%).

Teachers' psychobiographies reveal that the most common ways out from these crises are changing jobs (30.2\%), seeking help from colleagues and superiors (14\%) as well as retraining within the same profession (11.6\%). These ways characterize the initiative strategy of overcoming the crisis.

\section{Results:}

The results of the study are presented in tables 1,2,3.

Table 1. Factors of profession loss crisis

Loss of Profession Crisis

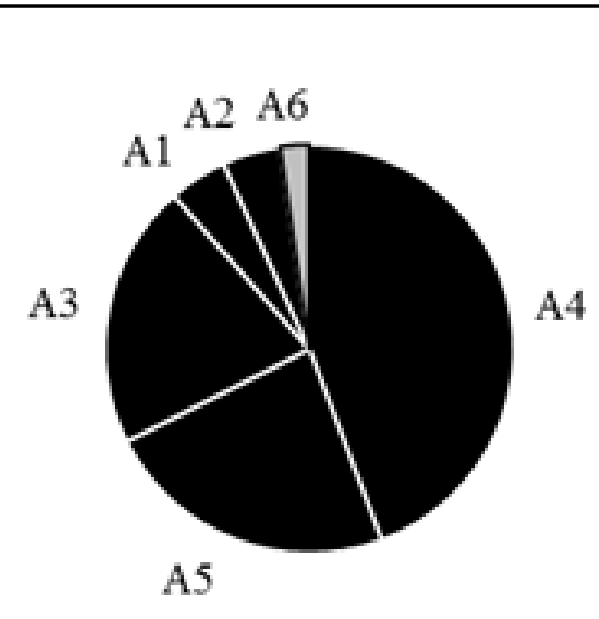

A1 - change in the social situation of development;

A2- age-related psychophysiological changes;

A3 - improvement or deterioration of social and economic conditions;

A4 - random events;

A5 - adverse circumstances

A6 - unsatisfied needs of an individual;

\section{Table 2. Emotions concerning profession loss crisis}

Loss of Profession Crisis

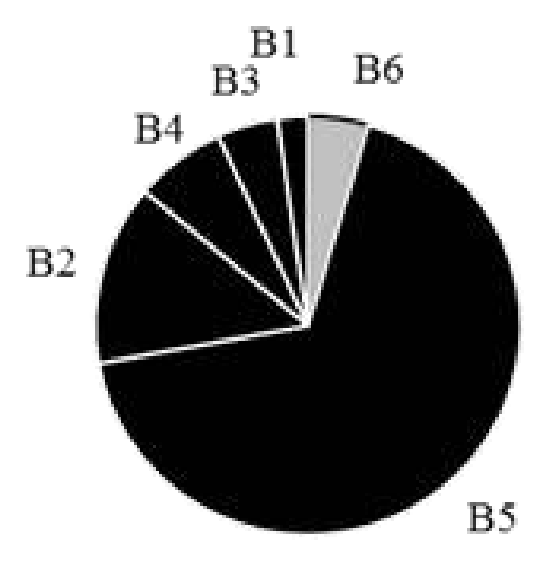

B1 - loss of meaning of educational and professional activities;

B2 - dissatisfaction with the process of performing the activity;

B3 - anxiety over a lack of opportunities for self-expression and self-actualization; B4 - lack of prospects for changing social and professional status; B5 - anxiety over a mismatch of professional activity with expectations; B6 - awareness of one's own incompetence;

Table 3. Strategies for coping with crisis Loss of Profession Crisis

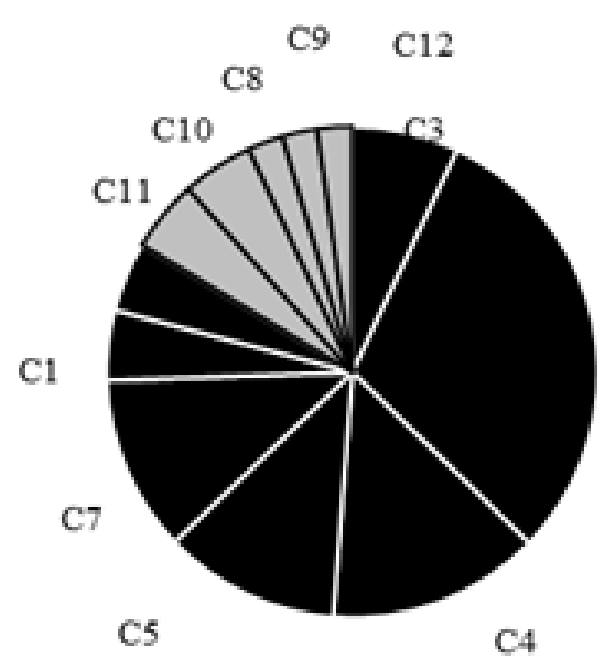

C1 - training and development;

$\mathrm{C} 2$ - change of job;

C3 - revision of the meaning of life and opportunities, drafting new scenarios of professional life;

C4 - seeking help from colleagues and administrators;

C5 - retraining within the same profession; C6 - return to the same workplace and position;

$\mathrm{C} 7$ - change of profession

C8 - finding the meaning of life in nonprofessional sphere

C9 - coping with the crisis due to pressure from parents, friends, and colleagues:

C10 a compromise resolution of a problem C10 - a compromise resolution of a problem that does not eliminate contradiction, but relieves stress;

C11 - gradual reconciliation with the activity; $\mathrm{C} 12$ - a random way out which turned out to be successful. 